\title{
Management of severe infections: A time to keep a cool head or a hot topic for clinical trials?
}

\author{
Kevin B Laupland MD Msc FRCPC ${ }^{1,2}$, Louis Valiquette MD MSc FRCPC 3
}

$\mathrm{B}$ acterial meningitis is a rare but serious infection that is associated with major adverse short- and long-term consequences (1-3). A key component of management is the early recognition and prompt administration of effective parenteral antimicrobial therapy. Even with adequate therapy, a significant number of cases are associated with adverse events, which may include cranial nerve palsies, vasculitis, hearing loss, visual impairment, cognitive impairment, seizures and vascular complications. In an effort to improve outcomes, several adjunctive therapies have been investigated. Most notably, the concomitant administration of systemic corticosteroids with antimicrobial therapy has been extensively investigated. While corticosteroids likely reduce complications, they do not improve all-cause mortality outcome in adults, with benefit only observed with Streptococcus pneumoniae (RR 0.84 [95\% CI 0.72 to 0.98]) $(4,5)$.

Neuroprotection with therapeutic hypothermia has been proposed as a potential adjunctive therapy for management of severe meningitis. Mourvillier et al (6) recently reported an open-label randomized controlled trial evaluating the effect of cerebral cooling on the outcome of severe bacterial meningitis. They randomly assigned patients with severe community-acquired bacterial meningitis and coma (Glasgow Coma Score $\leq 8$ ) admitted to French intensive care units (ICUs) between 2009 and 2011. The hypothermia group were therapeutically cooled to $32^{\circ} \mathrm{C}$ to $34^{\circ} \mathrm{C}$ for $48 \mathrm{~h}$ and then passively rewarmed. Control patients were treated with standard care. All patients received supportive therapies including antimicrobial therapy. The primary outcome was the Glasgow Outcome Scale score at three months. On the recommendation of the Data Safety and Monitoring Board, the trial was stopped after enrollment of 98 patients due to excess mortality in the hypothermia group (51\% versus 31\%; RR 1.99 [95\% CI 1.05 to 3.77]; $\mathrm{P}=0.04)$. At three months, unfavourable outcome was observed in $86 \%$ of hypothermia-treated patients compared with $75 \%$ of control patients (RR 2.17 [95\% CI 0.78 to 6.01]; $\mathrm{P}=0.13$ ). The authors concluded that therapeutic hypothermia did not improve outcome and may be harmful in patients with severe meningitis.

Several lines of evidence arising from animal experiments and from observational and clinical trials involving patients support the neuroprotective effects of brain cooling $(7,8)$. Two landmark studies found a major benefit for moderate $\left(32^{\circ} \mathrm{C}\right.$ to $\left.34^{\circ} \mathrm{C}\right)$ therapeutic hypothermia for patients resuscitated from cardiac arrest $(9,10)$. In addition to becoming a standard of care for patients with cardiac arrest, therapeutic hypothermia has also been applied to a range of other acute neurological insults.

So how can the worse outcome observed with therapeutic hypothermia in the Mourvillier et al (6) study be explained? One possibility is that the benefit of using therapeutic hypothermia is not hypothermia per se, but rather the avoidance of hyperthermia. This argument is supported, in part, by a recent large clinical trial that found no difference in outcome among post-cardiac arrest patients treated with a temperature target of $33^{\circ} \mathrm{C}$ versus $36^{\circ} \mathrm{C}$ (ie, avoidance of hyperthermia) (11). However, this still does not explain the excess mortality associated with therapeutic hypothermia observed in the Mourvillier et al (6) study. One may speculate as to whether potential benefits of induced hypothermia on neuroprotection may be countered by excess risks for other complications. While Mourvillier et al (6) did not observe excess non-neurological complications associated with hypothermia treatment, a significant body of literature exists supporting the major adverse effects of hypothermia on outcome of critically ill patients $(12-14)$. One mechanism to explain this effect is that hypothermia is immune suppressive and clearly increases the risk for development of infections in patients admitted to ICUs $(15,16)$.

While these data support the maintenance of normothermia in patients with meningitis, these results may not be generalizable to management of patients with severe infections who do not have neurological impairment. Indeed, in the absence of neurological compromise, there are several theoretical benefits to elevated body temperature. Fever is an evolutionary, adaptive response to infection and its presence inhibits growth of microorganisms, may reduce the expression of virulence factors, increases antimicrobial susceptibility and enhances immune responses (17). While complex, with many variables related to individual patient characteristics, the body of observational data involving $>500,000$ patients suggests that mild to moderate fever is associated with a better outcome than normothermia, especially among infected patients $(18,19)$. Clinical trials evaluating fever control strategies have not demonstrated overall benefit in neurologically intact patients in the $\operatorname{ICU}(20,21)$, with suggestion for potential harm observed in one study (22). It is somewhat curious, therefore, that collectively as clinicians, we have come to recognize fever as a pathological state that requires prompt pharmacological and physical correction. Surveys conducted around the globe indicate that $\geq 80 \%$ of clinicians report the need to treat even mild to moderate fever most or all of the time; however, such a practice is not supported or potentially even contrary to available evidence $(23,24)$.

\section{SUMMARY}

We believe that the study by Mourvillier et al (6) is an important addition to the infectious diseases literature and serves to guide our management of patients with severe meningitis. Based on this study and others, it is evident that hypothermia is a pathological state and prompt resuscitation to normothermia is warranted in patients with severe infections. In contrast, fever is an adaptive host response to infection and its presence is associated with improved outcome in neurologically intact, infected patients admitted to ICUs. While it may appear ridiculous to the many clinicians who insist on treating all fevers in infected patients, it is our contention that therapeutic hyperthermia requires (re-)exploration as an adjunctive therapy for selected patients with infection (25).

${ }^{1}$ Departments of Medicine, Critical Care Medicine, Pathology and Laboratory Medicine and Community Health Sciences, University of Calgary, Calgary, Alberta; ${ }^{2}$ Department of Medicine, Royal Inland Hospital, Kamloops, British Columbia; ${ }^{3}$ Department of Microbiology-Infectious

Diseases, Université de Sherbrooke, Sherbrooke, Quebec

Correspondence: Dr Kevin B Laupland, Royal Inland Hospital, 311 Columbia Street, Kamloops, British Columbia V2C 2T1.

Telephone 250-374-5111, e-mail klaupland@gmail.com 


\section{REFERENCES}

1. Campsall PA, Laupland KB, Niven DJ. Severe meningococcal infection: A review of epidemiology, diagnosis, and management. Crit Care Clin 2013;29:393-409.

2. Edmond K, Clark A, Korczak VS, Sanderson C, Griffiths UK, Rudan I. Global and regional risk of disabling sequelae from bacterial meningitis: A systematic review and meta-analysis. Lancet Infect Dis 2010;10:317-28.

3. Jit M. The risk of sequelae due to pneumococcal meningitis in high-income countries: A systematic review and meta-analysis. J Infect 2010;61:114-24.

4. Brouwer MC, McIntyre P, Prasad K, van de Beek D. Corticosteroids for acute bacterial meningitis. Cochrane Database Syst Rev 2013;(6):CD004405.

5. van de Beek D, de Gans J, Tunkel AR, Wijdicks EF. Communityacquired bacterial meningitis in adults. N Engl J Med 2006;354:44-53.

6. Mourvillier B, Tubach F, van de Beek D, et al. Induced hypothermia in severe bacterial meningitis: A randomized clinical trial. JAMA 2013;310:2174-83.

7. Zygun DA, Doig CJ, Auer RN, Laupland KB, Sutherland GR. Progress in clinical neurosciences: Therapeutic hypothermia in severe traumatic brain injury. Can J Neurol Sci 2003;30:307-13.

8. Wu TC, Grotta JC. Hypothermia for acute ischaemic stroke. Lancet Neurol 2013;12:275-84.

9. Bernard SA, Gray TW, Buist MD, et al. Treatment of comatose survivors of out-of-hospital cardiac arrest with induced hypothermia. N Engl J Med 2002;346:557-63.

10. Hypothermia after Cardiac Arrest Study Group. Mild therapeutic hypothermia to improve the neurologic outcome after cardiac arrest. N Engl J Med 2002;346:549-56.

11. Nielsen N, Wetterslev J, Cronberg T, et al. Targeted temperature management at 33 degrees $\mathrm{C}$ versus 36 degrees $\mathrm{C}$ after cardiac arrest. N Engl J Med 2013;369:2197-

12. Brivet F, Carras PM, Dormont J, et al. Hypothermia, a pertinent clinical prognostic factor in severe systemic inflammatory response syndrome. Crit Care Med 1994;22:533-4.

13. Tiruvoipati R, Ong K, Gangopadhyay H, Arora S, Carney I, Botha J. Hypothermia predicts mortality in critically ill elderly patients with sepsis. BMC Geriatr 2010;10:70.
14. Peres Bota D, Lopes Ferreira F, Melot C, Vincent JL. Body temperature alterations in the critically ill. Intensive Care Med 2004;30:811-6

15. Laupland KB, Zahar JR, Adrie C, et al. Severe hypothermia increases the risk for intensive care unit-acquired infection. Clin Infect Dis 2012;54:1064-70.

16. Kurz A, Sessler DI, Lenhardt R. Perioperative normothermia to reduce the incidence of surgical-wound infection and shorten hospitalization. Study of Wound Infection and Temperature Group. N Engl J Med 1996;334:1209-15.

17. Laupland KB. Fever in the critically ill medical patient. Crit Care Med 2009;37(7 Suppl):S273-8.

18. Lee BH, Inui D, Suh GY, et al. Association of body temperature and antipyretic treatments with mortality of critically ill patients with and without sepsis: Multi-centered prospective observational study. Crit Care 2012;16:R33.

19. Young PJ, Saxena M, Beasley R, et al. Early peak temperature and mortality in critically ill patients with or without infection. Intensive Care Med 2012 Jan 31 (Epub ahead of print).

20. Niven DJ, Stelfox HT, Laupland KB. Antipyretic therapy in febrile critically ill adults: A systematic review and meta-analysis. J Crit Care 2013;28:303-10.

21. Honarmand $\mathrm{H}$, Abdollahi M, Ahmadi A, et al. Randomized trial of the effect of intravenous paracetamol on inflammatory biomarkers and outcome in febrile critically ill adults. Daru 2012;20:12.

22. Schulman CI, Namias N, Doherty J, et al. The effect of antipyretic therapy upon outcomes in critically ill patients: A randomized, prospective study. Surg Infect 2005;6:369-75.

23. Saxena MK, Hammond NE, Taylor C, et al. A survey of fever management for febrile intensive care patients without neurological injury. Crit Care Resusc 2011;13:238-43.

24. Niven D, Laupland K, Tabah A, et al. Diagnosis and Management of Temperature Abnormality in ICUs: A EUROBACT Investigators Survey. Crit Care 2013;17:R289.

25. Simpson WM. Artificial fever therapy of syphilis and gonococcic infections. Br J Vener Dis 1936;12:133-66. 


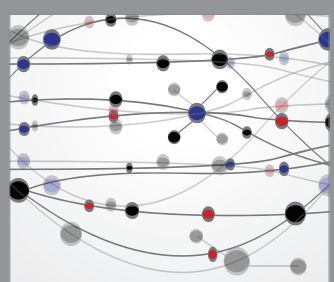

The Scientific World Journal
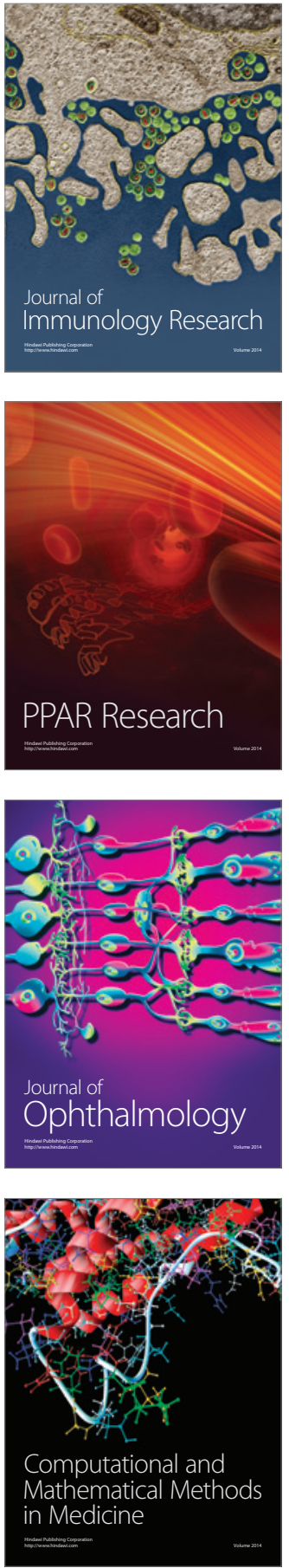

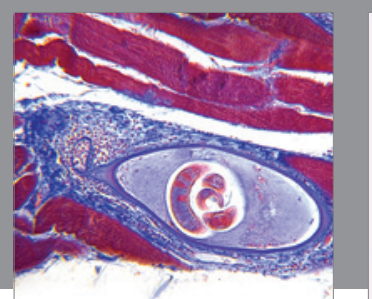

Gastroenterology Research and Practice

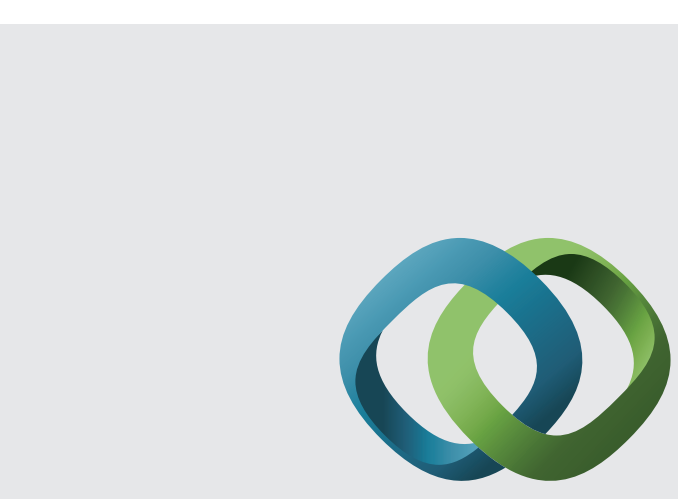

\section{Hindawi}

Submit your manuscripts at

http://www.hindawi.com
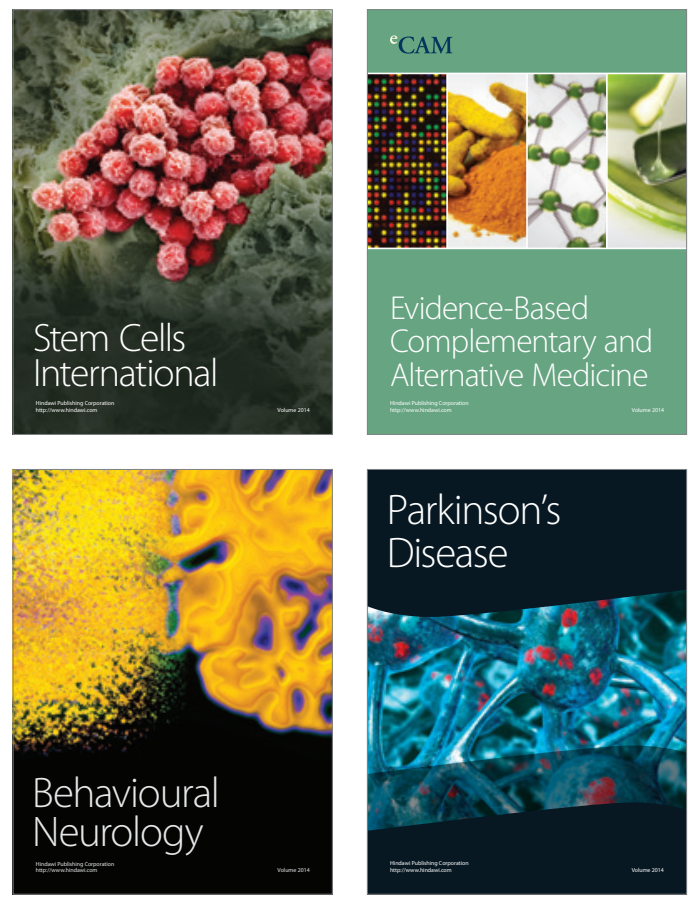
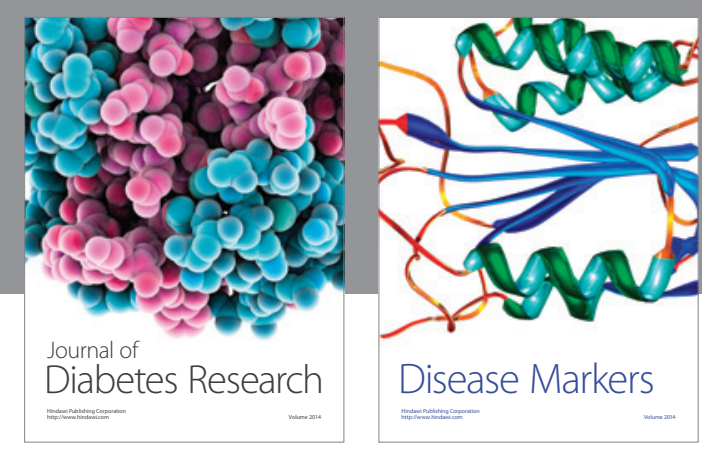

Disease Markers
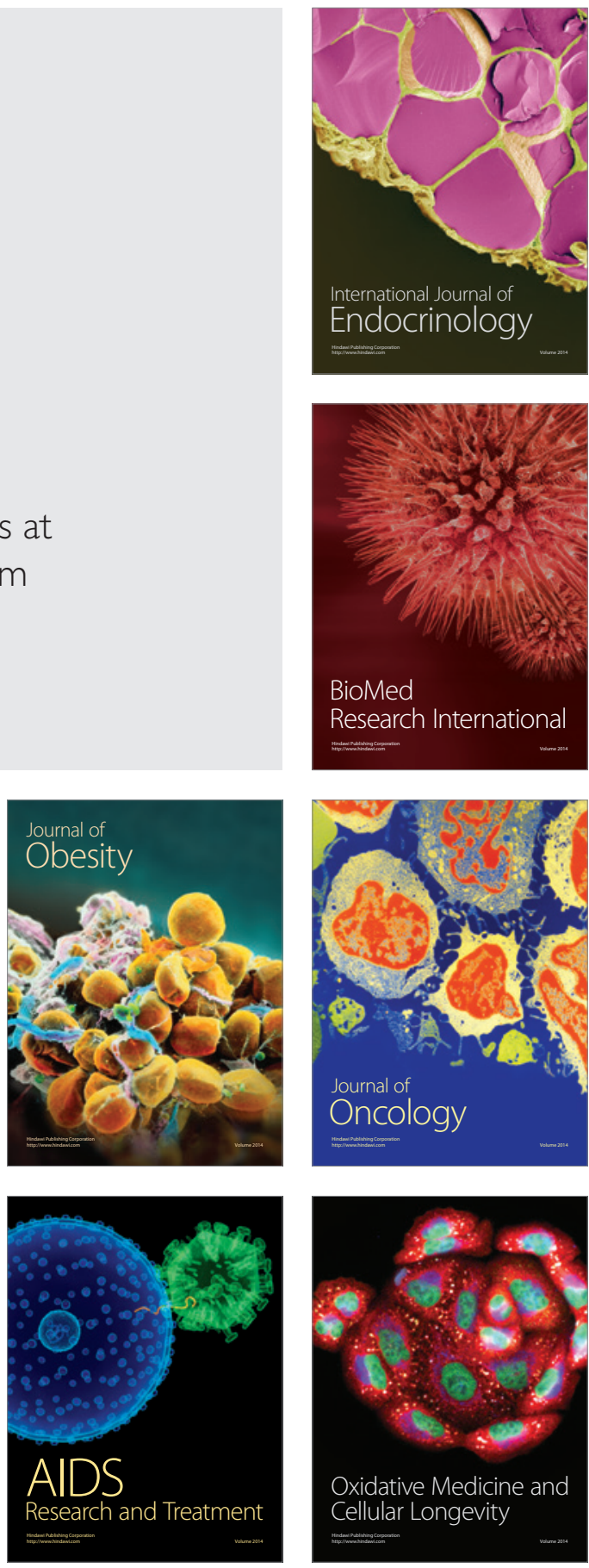